\title{
(2) OPEN ACCESS \\ Impact of emergency care centralisation on mortality and efficiency: a retrospective service evaluation
}

\author{
Christopher Price (10, ${ }^{1}$ Stephen McCarthy, ${ }_{1}^{2}$ Angela Bate, ${ }^{2}$ Peter McMeekin ${ }^{2}$
}

\begin{abstract}
- Additional material is published online only. To view please visit the journal online (http://dx.doi.org/10.1136/ emermed-2019-208539).
\end{abstract}

${ }^{1}$ Population Health Sciences Institute, University of Newcastle upon Tyne, Newcastle upon Tyne, UK

${ }^{2}$ Faculty of Health and Life Sciences, Northumbria University, Newcastle upon Tyne, UK

\section{Correspondence to} Dr Christopher Price, Population Health Sciences Institute, University of Newcastle, Newcastle upon Tyne, NE2 4AE, UK;

C.I.M.Price@newcastle.ac.uk

Received 22 February 2019 Revised 9 October 2019 Accepted 30 October 2019 Published Online First 7 January 2020

\section{Linked}

- http://dx.doi.org/10.1136/ emermed-2019-209248

Check for updates

(C) Author(s) (or their employer(s)) 2020. Re-use permitted under CC BY-NC. No commercial re-use. See rights and permissions. Published by BMJ.

To cite: Price C, McCarthy S, Bate A, et al. Emerg Med J 2020:37:180-186.

\begin{abstract}
Objective Evidence favours centralisation of emergency care for specific conditions, but it remains unclear whether broader implementation improves outcomes and efficiency. Routine healthcare data examined consolidation of three district general hospitals with mixed medical admission units (MAU) into a single highvolume site directing patients from the ED to specialty wards with consultant presence from 08:00 to 20:00. Methods Consecutive unscheduled adult index admissions from matching postcode areas were identified retrospectively in Hospital Episode Statistics over a 3-year period: precentralisation baseline (from 16 June 2014 to 15 June $2015 ; n=18586$ ), year 1 postcentralisation (from 16 June 2015 to 15 June 2016; $n=16126$ ) and year 2 postcentralisation (from 16 June 2016 to 15 June 2017; $n=17$ 727). Logistic regression including key demographic covariates compared baseline with year 1 and year 2 probabilities of mortality and daily discharge until day 60 after admission and readmission within 60 days of discharge.
\end{abstract}

Results Relative to baseline, admission postcentralisation was associated with favourable $\mathrm{OR}$ $(95 \% \mathrm{Cl})$ for day 60 mortality (year 1: $0.95(0.88$ to $1.02), p=0.18$; year 2: 0.94 (0.91 to 0.97$), p<0.01)$, mainly among patients aged $80+$ years (year $1: 0.88$ (0.79 to 0.97$)$; year 2: $0.91(0.87$ to 0.96$))$. The probability of being discharged alive on any day since admission increased (year 1: 1.07 (1.04 to 1.10), $p<0.01$; year 2: $1.04(1.02$ to 1.05$), p<0.01)$ and the risk of readmission decreased (year 1: 0.90 (0.87 to $0.94), p<0.01$; year 2: 0.92 (0.90 to 0.94$), p<0.01)$.

Conclusion A centralised site providing early specialist care was associated with improved short-term outcomes and efficiency relative to lower volume ED admitting to MAU, particularly for older patients.

\section{INTRODUCTION}

Current healthcare policy favours centralisation of emergency medical care for the most seriously ill patients, but it is unclear how broad implementation will impact on health outcomes and service efficiency. ${ }^{12}$ Regional approaches have proven successful for specific conditions requiring timecritical interventions delivered by expert multidisciplinary teams, such as major trauma, myocardial infarction and stroke. ${ }^{3-6}$ In contrast, many unscheduled district general hospital (DGH) admissions reflect exacerbations of long-term conditions and functional decompensation of frail patients provoked by minor illness. ${ }^{7-9}$ These groups often require simpler or symptomatic management strategies, and outcomes may be harder to influence by

\section{Key messages}

What is already known on this subject

- Current national policy favours centralisation of emergency medical care based on evidence of improved outcomes and efficiency for specific conditions.

- The number, age and complexity of emergency admissions are increasing in real terms.

- It is unclear whether centralisation is justified for unselected emergency admissions reflecting older, frailer patients with a broad range of conditions.

\section{What this study adds}

- Unscheduled adult index admissions were identified in Hospital Episode Statistics from a single large NHS Trust to examine the impact of emergency care centralisation over a 3-year period: precentralisation baseline (from 16 June 2014 to 15 June 2015; $n=18$ 586), year 1 postcentralisation (16 June 2015 to 15 June $2016 ; n=16126)$ and year 2 postcentralisation (from 16 June 2016 to 15 June 2017; n=17 727).

- The probability of day 60 mortality was reduced when three district general hospital EDs were centralised at a new high-volume emergency care hospital with earlier specialist contact.

- The greatest mortality reduction was observed among the oldest patients (aged 80+ years) with potentially treatable conditions such as pneumonia and heart failure.

- Although length of stay increased during the first year postcentralisation, the average probability of discharge per day was higher with a reduced risk of readmission.

centralisation alone. Concentration of healthcare resources at higher volume sites might facilitate processes associated with improved survival, such as earlier senior medical review, ${ }^{10}{ }^{11}$ but it remains unclear whether regionalisation without preselection can provide effective specialist care and better outcomes for a standard undifferentiated emergency admission population. ${ }^{12}$ Reconfiguration also creates challenges for capacity and efficiency that threaten to offset gains made by better initial clinical care. ${ }^{13}$ Delayed repatriation for individuals needing local rehabilitation or social support can extend overall hospitalisation, during which pressures to discharge sooner might precipitate early readmission. ${ }^{1415}$ 
Table 1 Service coverage across the three DGH ED sites

\begin{tabular}{llll}
\hline DGH & Total population served & People resident per square kilometre & Population description \\
\hline North Tyneside & 235000 & 2401 & Uniform urban and suburban city population all within 15 kilometres of the ED. \\
$\begin{array}{l}\text { Wansbeck } \\
\text { Hexham }\end{array}$ & 255000 & 603 & $\begin{array}{l}\text { Majority in } 5 \text { towns between } 1 \text { and } 80 \text { kilometres from the ED, remainder rural. } \\
\text { Majority within } 10 \text { kilometres of the ED in a single town, the rest widely } \\
\text { dispersed. }\end{array}$ \\
\hline
\end{tabular}

DGH, district general hospital.

To understand the impact of whole-system centralisation for unselected emergency admissions, we observed the consolidation of three DGH EDs with mixed medical admission units into a single large site providing only acute care with early specialist input. The objectives were to compare prereconfiguration and postreconfiguration demographic characteristics for index admissions, all-cause and condition-specific mortality, and general indicators of service efficiency.

\section{METHODS}

\section{Setting}

Northumbria Healthcare NHS Foundation Trust (NHFT) is an acute and elective care provider for approximately 550000 people across a large geographical area of North East England. Prior to 16 June 2015, all medical emergencies (operatordispatched and general practitioner-requested ambulances) were admitted to mixed medical admission units via three DGH EDs (table 1): North Tyneside General Hospital (North Shields, Tyne and Wear), Wansbeck General Hospital (Ashington, Northumberland) and Hexham General Hospital (Hexham, Northumberland). There were no general practitioner admissions directly to the admissions units, that is, there was a 'single front door' model via ED. Exceptions were patients with ST-elevation myocardial infarction or complex major trauma, who were redirected by the ambulance service to nearby regional cardiology and trauma centres and are not included in this report. The EDs were approximately 30 kilometres apart in a triangular distribution. The mean ambulance journey distance from incident locations to the nearest site was 17 kilometres (SD 19 kilometres), lasting $15 \mathrm{~min}$ (SD $12 \mathrm{~min}$ ). After admission, patients were reviewed at least once daily (including weekends) by an on-call medical or surgical consultant and either discharged or transferred to an appropriate ward within 12-24 hours if further inpatient care was required. Each site supported surgical and orthopaedic review, but transfers were sometimes required for treatment; for example, the smallest site did not host orthopaedic trauma surgery. A critical care outreach team was always available. Between July 2014 and June 2015, the NHFT Summary Hospital-level Mortality Indicator value was within the national range for satisfactory performance at $1.042(95 \%$ control interval adjusted for overdispersion: 0.906-1.104). ${ }^{16}$

After 16 June 2015, all medical emergencies were admitted to a single new emergency care hospital (ECH) located in-between the North Tyneside and Wansbeck sites (Cramlington,

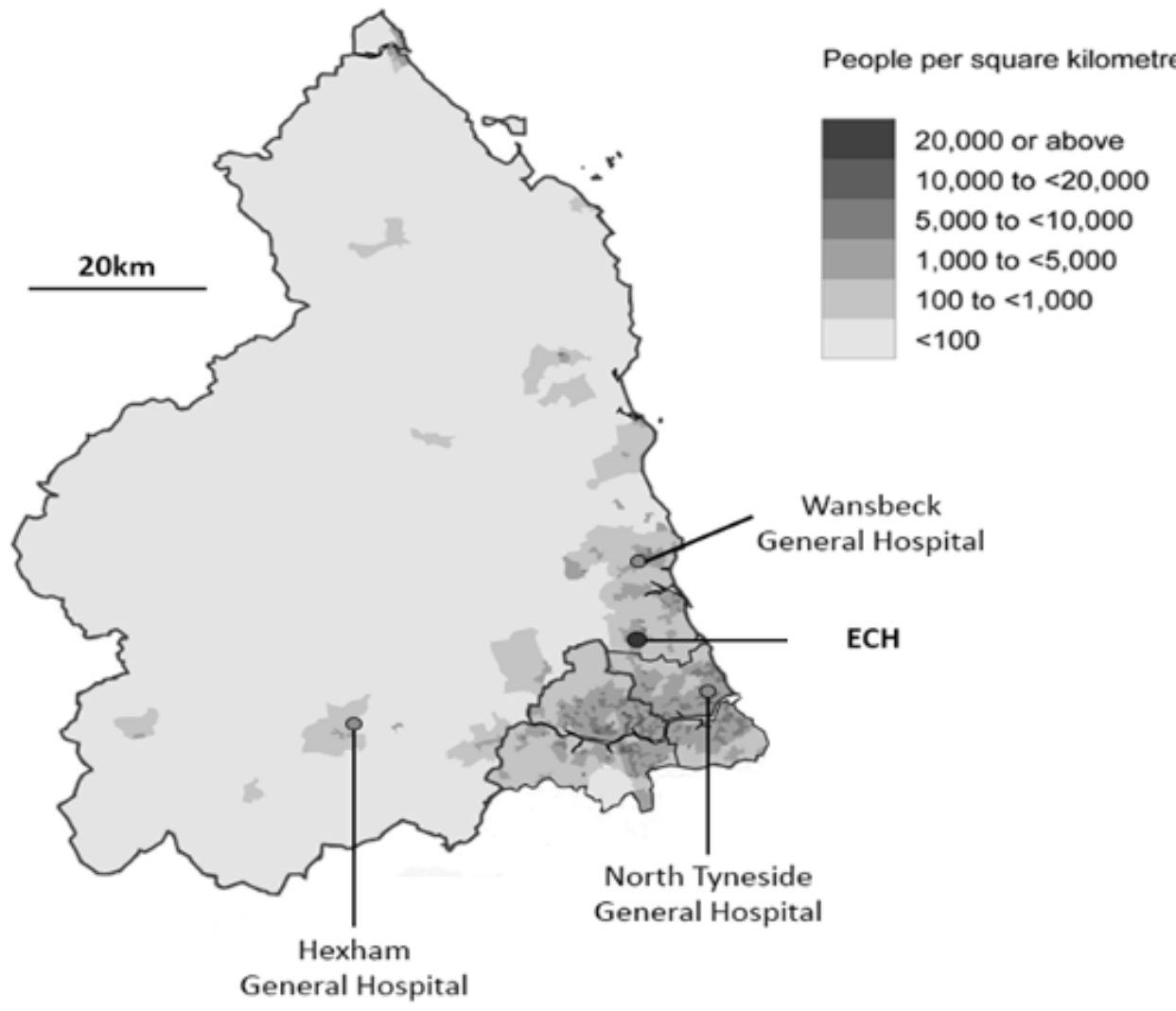

Figure 1 Population density of the geographical area served with approximate locations for the three previous ED sites and the new emergency care hospital (ECH). 
Table 2 Demographic characteristics and descriptive outcomes for all cases per year

\begin{tabular}{lcccr}
\hline & Baseline & ECH year 1 & ECH year 2 & P value \\
\hline Number of index admissions & 18586 & 16126 & 17727 & \\
Male (\%) & $7856(42.3)$ & $7060(43.8)$ & $7690(43.4)$ & 0.012 \\
Age, mean years (SD) & $67.0(20.2)$ & $67.9(19.3)$ & $68.3(19.1)$ & $<0.001$ \\
\hline Age, median years (IQR) & $72(53-83)$ & $72(56-83)$ & $73(56-83)$ & $<0.001$ \\
\hline CCI, mean (SD) & $1.54(2.12)$ & $1.66(2.19)$ & $1.74(2.24)$ & $<0.001$ \\
\hline IMDS, mean (SD) & $24.7(15.3)$ & $24.2(15.1)$ & $24.0(15.0)$ & $<0.001$ \\
Day 60 deaths (\%) & $1729(9.3)$ & $1488(9.2)$ & $1574(8.9)$ & 0.334 \\
\hline Inpatient deaths (\%) & $931(5.0)$ & $831(5.1)$ & $854(4.8)$ & 0.362 \\
\hline Postdischarge deaths (\%) & $798(4.3)$ & $657(4.1)$ & $720(4.1)$ & 0.454 \\
Inpatient days, mean (SD) & $6.2(13.8)$ & $6.8(15.5)$ & $5.8(12.3)$ & $<0.001$ \\
Inpatient days, median (IQR) & $1(0-6)$ & $1(0-6)$ & $1(0-6)$ & $<0.001$ \\
\hline Readmissions (\% discharged & $3752(21.3)$ & $3001(19.6)$ & $3177(18.8)$ & $<0.001$ \\
alive) & & & & \\
\hline
\end{tabular}

$\mathrm{P}$ values represent the trend across all 3 years $\left(\chi^{2}\right.$ for categorical and Kruskal-Wallis for continuous variables).

$\mathrm{CCl}$, Charlson Comorbidity Index; ECH, emergency care hospital; IMDS, Index of Multiple Deprivation Score.

Northumberland). The reconfiguration did not intend to alter the service boundary or access routes, that is, 999 call, primary care referral and self-presentation. The average ambulance journey distance and duration were now 22 kilometres miles (SD 21 kilometres) and $16 \mathrm{~min}$ (SD $13 \mathrm{~min}$ ), reflecting longer journeys but a favourable road network. Figure 1 shows a population density map of the geographical area served, with approximate locations indicated for the three previous ED sites and the new $\mathrm{ECH}$.

Following initial clinical review, patients requiring admission pass directly to the most relevant specialty with a target time of less than 4 hours: cardiology, gastroenterology, respiratory, stroke, internal medicine, geriatric medicine, general surgery, orthopaedic trauma and critical care. Each has ward-based senior specialist presence for 12 hours per day, 7 days a week and on-call availability overnight. Consultants in emergency medicine and critical care are present on site at all times. Inpatients are reviewed at least twice daily to consider discharge or transfer to their local DGH site for ongoing treatment, usually within 72 hours of admission. Each former DGH ED site has become a walk-in urgent care centre open 24 hours, with ambulance transfer to the $\mathrm{ECH}$ if patients require admission. There were no separate major changes planned in hospital or social care during the study period, including pre-existing regional cardiology and trauma services or community palliative care.

Table 3 Influences on day 60 mortality (baseline cases plus ECH year 1 or ECH year 2)

\begin{tabular}{|c|c|c|c|c|}
\hline & \multicolumn{2}{|l|}{$\begin{array}{l}\mathrm{ECH} \text { year } 1 \\
\mathrm{n}=34712\end{array}$} & \multicolumn{2}{|l|}{$\begin{array}{l}\text { ECH year } 2 \\
n=36313\end{array}$} \\
\hline & OR $(95 \% \mathrm{Cl})$ & $P$ value & OR $(95 \% \mathrm{Cl})$ & $P$ value \\
\hline Age (years) & 1.09 (1.06 to 1.11$)$ & $<0.001$ & 1.07 (1.05 to 1.09$)$ & $<0.001$ \\
\hline Male gender & 1.31 (1.21 to 1.41$)$ & $<0.001$ & 1.29 (1.20 to 1.39$)$ & $<0.001$ \\
\hline $\mathrm{CCl}$ & 1.19 (1.17 to 1.20$)$ & $<0.001$ & $1.17(1.15$ to 1.19$)$ & $<0.001$ \\
\hline IMDS & 1.00 (1.00 to 1.01$)$ & 0.025 & 1.00 (1.00 to 1.01$)$ & 0.003 \\
\hline ECH admission & 0.95 (0.88 to 1.02$)$ & 0.184 & 0.94 (0.91 to 0.97$)$ & 0.001 \\
\hline
\end{tabular}

$\mathrm{CCl}$, Charlson Comorbidity Index; ECH, emergency care hospital; IMDS, Index of Multiple Deprivation Score.

\section{Population}

The cohort consisted of consecutive adult (aged 18+ years) unscheduled index admissions identified in Hospital Episode Statistics (HES) data during a 3-year period: precentralisation baseline (from 16 June 2014 to 15 June 2015), postcentralisation ECH year 1 (from 16 June 2015 to 15 June 2016) and postcentralisation ECH year 2 (from 16 June 2016 to 15 June 2017). Patients admitted directly to a specialty from another NHS Trust or primary care were excluded. To qualify as an index admission it was necessary that the length of stay was at least 1 day or ended in death on the day of arrival, and there had been no unscheduled hospitalisation during the previous 60 days. Outside of this window, individual patients could feature as separate admissions on multiple occasions throughout the 3 years. In order to minimise the case-mix impact of any unintended shift in service boundary following ED relocation to the new ECH site, index admissions were only included from each residential postcode prefix area if annual contributions during two of the 3 years were at least $50 \%$ of the highest yearly total observed from the same area. Localities were automatically excluded if they did not contribute any admissions during one or more of the 3 years. Although this approach excluded cases from the analysis, it ensured that the impact of the reconfiguration was based on a core population with more consistent health and social needs, and primary care provision.

\section{Outcomes}

Data are reported for all index admissions $(18+$ years) and three age bands: $18-64,65-79$ and $80+$ years. In addition to standard demographic characteristics, the Charlson Comorbidity Index $(\mathrm{CCI})^{17}$ was calculated for each admission and the Index of Multiple Deprivation Score (IMDS) was derived from Lower Super Output Areas. ${ }^{18}$ The health impact of the reconfiguration was examined by the probability of death at day 60 after admission irrespective of discharge status (ie, total mortality). Death at day 60 is also reported separately for inpatient and postdischarge groups. Other outcomes were the total number of continuous inpatient days per admission (ie, including days at a local DGH if patients were transferred rather than discharged from ECH), the average daily probability of discharge for inpatients up to day 60 after admission, and separate probabilities for ED reattendance and readmission within 60 days of discharge (as a proportion of those patients discharged alive). If there was $>1$ ED reattendance or readmission within 60 days of discharge, only the first event contributed towards each analysis. The primary discharge code from each continuous spell in hospital was categorised to summarise yearly case-mix using the Healthcare Cost and Utilization Project Clinical Classifications Software (CCS) for the International Classification of Diseases 10 (https://www.hcup-us. ahrq.gov/toolssoftware/ccs10/ccs10.jsp).

\section{Statistical analysis}

Examination for trends across all three cohort years was made by $\chi^{2}$ for categorical and Kruskal-Wallis for continuous variables. Multivariate logistic regression models including important demographic characteristics were used to determine associations between the outcomes (ie, day 60 mortality, average daily probability of discharge, ED reattendance and readmission) and the timing of index admissions relative to the reconfiguration (pre-ECH/post-ECH). ECH year 1 and $\mathrm{ECH}$ year 2 results are presented and compared separately to show any transition effects. In order to consistently deal with death as a competing risk, a technique based on Fine and Gray's ${ }^{19}$ proportional 
subhazards model estimated times to events of interest. Unadjusted OR compared the risk of hospital mortality for each CCS category during ECH year 1 and $\mathrm{ECH}$ year 2 relative to baseline. To minimise spurious statistical associations, comparisons were limited to categories with at least 10 inpatient deaths/year. A formal sample size calculation was not performed in advance as there was no information available to inform the effect size of emergency care centralisation in this model and setting. The number of cases in the analysis reflects the available data over the 3-year time period.

Analysis was conducted using STATA V.15.1. The NHS Trust Clinical Information Department undertook anonymisation of the data before these were securely transferred to the authors for analysis. No patient identifiable data are reported. Individual members of the public were not directly involved in any aspect of the project.

\section{RESULTS}

Over 3 years there were 52439 index admissions which met the cohort definition (table 2; online supplementary table S2 describes the cohort characteristics by age bands). The median (IQR) index admissions/patient was the same in each of the 3 years at 1 (1-2). The smaller number of total cases in $\mathrm{ECH}$ year 1 resulted from the exclusion of postcodes that had each contributed less than half of the baseline number before reconfiguration, possibly reflecting unplanned temporary changes in the service boundary.

Each ECH year showed increasing age and comorbidities among admissions, contrasting with an opposite trend towards a minor absolute reduction in the overall proportion of day 60 deaths, which was not statistically significant. In the $80+$ years age band, the crude death rate fell from a baseline of $16.7 \%$ to $15.1 \%$ in $\mathrm{ECH}$ year 1 and $14.8 \%$ in $\mathrm{ECH}$ year 2, a relative reduction of $11.3 \%$ from baseline (see online supplementary table S2). The median number of inpatient days remained unchanged, but the mean and SD increased in ECH year 1 before falling in ECH year 2, suggesting that the new system initially contained a small group of patients requiring longer periods of hospitalisation.

Separate regression analyses using baseline cases combined with those from ECH year 1 or ECH year 2 showed typical demographic influences on day 60 mortality, that is, increasing risk with male gender and increasing age, CCI and IMDS (table 3). However the direction of the association with admission to the ECH rather than a DGH was consistent with a survival advantage, which reached statistical significance in ECH year 2.

Table 4 shows the ECH year 1 and ECH year 2 postreconfiguration probabilities relative to baseline for all outcomes and age bands. The reduction in risk of day 60 mortality after ECH was mainly evident among admissions for $80+$ years for both inpatient and postdischarge groups. There was no statistically significant impact on mortality among the 18-64 years group in ECH year 1 or ECH year 2. Comparison of overall day 60 mortality in ECH year 1 and year 2 showed a reduction during year 2 (OR $0.93(0.85$ to 1.00$)$ ), which was limited to only inpatient deaths when examined by discharge status (see online supplementary table S4). Within each of the three age groups, there were no significant differences in mortality between ECH year 1 and year 2, although the power to detect an effect was reduced.

The average probability of discharge per day was increased consistently across all age bands. This did not increase the risk of readmission, which was significantly reduced. Reattendance at ED during ECH year 1 showed an increased probability 
Table 5 Clinical Classifications Software categories with at least 10 inpatient deaths/year showing an important difference in hospital mortality $(p<0.05)$ in $\mathrm{ECH}$ year 1 and/or ECH year 2 relative to baseline

\begin{tabular}{|c|c|c|c|c|c|c|c|c|c|c|}
\hline \multirow[b]{2}{*}{ Clinical Classifications Software category } & \multicolumn{2}{|c|}{ Baseline } & \multicolumn{4}{|c|}{ ECH year 1} & \multicolumn{4}{|c|}{ ECH year 2} \\
\hline & Cases & $\begin{array}{l}\text { Inpatient } \\
\text { deaths }\end{array}$ & Cases & $\begin{array}{l}\text { Inpatient } \\
\text { deaths }\end{array}$ & $\begin{array}{l}\text { Death, OR } \\
(95 \% \mathrm{CI})\end{array}$ & $P$ value & Cases & $\begin{array}{l}\text { Inpatient } \\
\text { deaths }\end{array}$ & Death, OR $(95 \% \mathrm{Cl})$ & $P$ value \\
\hline Pneumonia (except caused by TB or STI) & 1058 & 228 & 894 & 156 & $0.80(0.63$ to 1.01$)$ & 0.06 & 1167 & 190 & 0.84 (0.75 to 0.94$)$ & 0.002 \\
\hline Congestive heart failure (non-hypertensive) & 337 & 57 & 308 & 48 & 0.91 (0.59 to 1.4$)$ & 0.66 & 326 & 34 & $0.73(0.57$ to 0.92$)$ & 0.009 \\
\hline Aspiration pneumonitis & 102 & 47 & 101 & 24 & 0.36 (0.19 to 0.68$)$ & 0.001 & 90 & 26 & $0.69(0.51$ to 0.94$)$ & 0.018 \\
\hline
\end{tabular}

ECH, emergency care hospital; STI, sexually transmitted infection; TB, tuberculosis.

among the 18-64 years group, but no overall difference due to a reduction among the $80+$ years group and a reduction across all groups during ECH year 2. Online supplementary table S4 shows that the probability of ED reattendance was lower in $\mathrm{ECH}$ year 2 when compared with ECH year 1 across all age groups separately and in combination (OR 0.72 (95\% CI 0.67 to 0.78$)$ ), implying a trend towards improved performance. During ECH year 2 there was also a reduction in readmissions (OR 0.93 (0.89 to 0.99$)$ ) despite an increase in the probability of discharge (OR 1.03 (1.01 to 1.05$)$ ) relative to $\mathrm{ECH}$ year 1 .

Primary discharge codes across the whole cohort generated 230 CCS categories (listed in online supplementary table S5 with corresponding numbers of inpatient deaths per year). Table 5 shows those categories with at least 10 inpatient deaths/year and a statistically important difference $(\mathrm{p}<0.05)$ in the probability of hospital mortality between baseline and $\mathrm{ECH}$ year 1 or $\mathrm{ECH}$ year 2. Reductions were observed for cardiorespiratory conditions especially infection. After reconfiguration there were no increases in hospital mortality for conditions with at least 10 inpatient deaths/year.

\section{DISCUSSION}

This service evaluation provides limited real-world evidence of an inpatient and postdischarge survival advantage for unselected emergency admissions at a higher volume ECH promoting early specialist review when compared retrospectively with a standard DGH model serving the same population. The effect appeared to be related to fewer deaths within the oldest age band $(80+$ years), particularly from cardiorespiratory conditions, and was greatest during the second year after the ECH opened. Reconfiguration was generally associated with improved probabilities for discharge and readmission, but a longer inpatient stay during the first year.

\section{Limitations}

Observational studies are subject to known and unknown influences on outcomes, although chance variation is partly offset by a large volume of events. It was not possible to perform randomisation, and an interrupted time series technique was not used due to concerns about non-linearity and time-varying external effects, especially seasonal demands. It is feasible that observations post-ECH are not attributable to the service change and may have occurred as part of a longer term trend, which has not been identified because the baseline interval was only 12 months; for example, a coincidental increase in community palliative care could have reduced the proportion of admissions with a high short-term mortality risk. We did not have access to data to create a synthetic control group matched by demographic and disease characteristics, which could have considered whether wider trends influenced results (eg, simultaneous national reductions in hospital deaths), although this approach would not reflect important local influences on outcomes such as clinical pathways, community services and therapeutic practices.

To minimise the effect of an unintended boundary shift towards a population with different health needs and community care, postcodes were only included if there was at least 50\% agreement in the number of cases before and after reconfiguration. It is also important to note that the outcomes relate to 12 months of index admissions without an unscheduled hospitalisation for 60 days previously, and different results might have been obtained without efforts to standardise the cohort. Other important demographic influences on mortality were considered, but data were not available to consider illness severity or the availability of specific components of care such as Intensive Care Unit bed availability. It was not possible to comment on whole-system influences such as contact with primary care and social care provision, activity at neighbouring ED, ambulance service resources or the consequences of reconfiguration for admissions aged under 18 years. It is also unknown whether the $\mathrm{ECH}$ influenced the proportion of ED attendees who were not admitted, but it is likely that any inappropriate 'failures to admit' would have reattended soon afterwards and thereby included in the admissions data. The reconfiguration did not coincide with the introduction of powerful new treatments, but it is feasible that baseline DGH performance might also have benefited from the additional financial investment and operational processes related to establishing a large central ED.

\section{Comparison with previous findings}

National policy proposes that centralisation will deliver effective and efficient care for the sickest patients, but there is little evidence available describing real-world advantages for unselected ED populations in the context of increasing demand and illness complexity. In 2016-2017 there were nearly 5.8 million emergency admissions in the NHS, a growth of $24 \%$ over the last 10 years and $2.1 \%$ since the previous year. ${ }^{7}$ Older patients at risk of frailty are increasing more than any other group, which concurs with the CCI trend observed within our cohort. ${ }^{7-9}$ It is therefore directly relevant that the main health impact of the $\mathrm{ECH}$ reconfiguration was a consistent reduction in the probability of death for admissions aged 80 years and over. Persistence of a postdischarge effect makes it unlikely that this was not simply due to quick identification and discharge of palliative cases. The lack of impact observed among younger admissions might reflect the lower power for detecting an effect as death is a rarer event and/or indicate that the content of care did not differ considerably following the reconfiguration.

The outcomes observed are consistent with other evaluations describing the impact of streamlining emergency care for all non-elective admissions. There was a significant trend towards improved mortality when all medical assessment unit activity within one large NHS hospital was relocated to the ED 
following the introduction of short-stay ( 72 hours) medical and surgical wards, greater specialist input, more efficient care pathways and better access to emergency radiology. ${ }^{20}$ In comparison with 23 other similar NHS sites during the postintervention period, the intervention hospital had the lowest hospital standardised mortality ratios for non-elective admissions and lowest standardised admission ratios for the catchment population. ${ }^{21}$

A more recent controlled interrupted time series to assess the impact of closing five NHS EDs in different localities reported increases in ambulance service incidents and the time taken to get to hospital, but there was no statistical evidence of an association with mortality. ${ }^{22}$ It was not possible to judge whether any detrimental effect from additional travel was offset by better care received at the next hospital. In the setting we describe there was only a small increase in average journey time, but the reconfiguration resulted in enhanced contact with senior medical staff at a site with higher specialty case volumes. In England, a survey of medical staffing linked with HES outcomes between April 2009 and March 2010 from 91 acute hospital sites showed that an admitting consultant presence within the acute medicine unit for a minimum of 4 hours per day (65\% of study group) had a lower adjusted case fatality rate and readmission rate compared with sites below 4 hours. ${ }^{10}$ The largest effect was across hospitals with at least 40 acute medical admissions daily. In other healthcare systems, observational studies using national data sets have shown that higher site case volumes are associated with lower short-term mortality for myocardial infarction, heart failure, ischaemic stroke, acute exacerbations of chronic obstructive pulmonary disease and surgically treated hip fracture in Germany, ${ }^{1123}$ and myocardial infarction, pneumonia, heart failure and acute exacerbations of chronic obstructive pulmonary disease in the USA. ${ }^{24}{ }^{25}$ These observations are consistent with the ECH model and are believed to reflect greater clinical expertise, adherence to clinical guidelines and multidisciplinary teamwork.

To date, large-scale emergency care reconfigurations have been driven by evidence for better outcomes and efficiency of service provision and prehospital pathways for specific conditions, particularly if a time-critical treatment is available such as intravenous thrombolysis for ischaemic stroke. ${ }^{6}$ There are no previous reports of undifferentiated centralisation benefiting a typical emergency admission population in an NHS Trust where the main impact was earlier specialist review rather than deployment of new therapies. The clearest improvement in condition-specific inpatient survival postreconfiguration was for pneumonia \pm aspiration, a common scenario among older and frailer patients which is likely to reflect earlier diagnosis and coordinated multidisciplinary care. The ECH does not provide emergency primary percutaneous coronary intervention but benefit was still observed for heart failure. Stroke mortality was unaffected, but this probably reflects the trust-wide specialist service which was already established. Changes among other CCS groups did not reach statistical significance for benefit or harm, although many lacked statistical power due to the small number of inpatient deaths per year. It was not possible to examine condition groups and mortality after discharge because HES does not include community deaths and it could not be assumed that the CCS category at discharge would be the condition responsible.

After reconfiguration the average daily probability for discharge was higher and readmission probability was reduced, consistent with evidence that access to multidisciplinary specialist teams during emergency hospitalisation can improve efficiency as well as health. ${ }^{6}{ }^{10}{ }^{21}$ However, ED reattendance increased during ECH year 1 among the youngest group before reduction across all age bands during ECH year 2 relative to baseline and year 1, which might reflect initial rapid turnover of the most stable patients before sufficient measures were in place for immediate continuation of outpatient care. It is also likely that a more effective social care response occurred for there to be a reduction in reattendances by older persons as well as the shorter length of stay observed during ECH year 2 .

\section{Future implications}

If non-selective centralisation of emergency care is to continue as a favoured model, there are a number of observations which require further evaluation. Despite regression analysis showing an improved probability of discharge per day, the average length of hospitalisation increased in ECH year 1 before falling in $\mathrm{ECH}$ year 2. Further examination of this transient effect should consider an initial shift in case-mix towards admissions with greater dependency than represented by the CCI, delayed local repatriation, general redistribution of healthcare resources from rehabilitation to emergency sectors, and extended stay by a small group of complex survivors created by early specialist management before the system adapted to optimise discharges. There was a similar chronological pattern with mortality reduction, which was only statistically significant in ECH year 2, possibly reflecting that time is required for consolidation of new care pathways and development of multidisciplinary expertise.

To assist with wider implementation, it will be necessary to consider barriers and facilitators for achieving whole service performance targets, especially during a transition phase, and attempts to define longitudinal control groups. Inclusion of markers for illness severity will confirm which patients are the main beneficiaries, whereas linkage between HES and cause of death in the community will provide additional information about mechanisms of benefit or harm. Longer term outcomes in the context of wider health and community service changes are needed to understand sustainability, contextualised by social care utilisation and public views.

In summary, routine healthcare data have shown that a central site facilitating rapid transfer of undifferentiated non-elective admissions from the ED to on-site specialties with a high presence of senior medical staff appears to be effective and efficient in the short term and is consistent with evidence showing better outcomes for key conditions treated at higher volume sites. Older patients had the best probability of a better outcome, but further evaluation is required to confirm that this observation specifically resulted from the service change and to confirm the main underlying mechanisms.

Contributors $C P$ and PM conceived and designed the project. CP, SM, AB and PM acquired, analysed and interpreted the data. CP drafted the first version of the manuscript. CP, SM, AB and PM drafted the subsequent versions of the manuscript. The corresponding author attests that all listed authors meet the authorship criteria and that no others meeting the criteria have been omitted.

Funding This study was funded by Dunhill Medical Trust (Research Grant R357/0514). The funder and clinical service did not influence the design, analysis or reporting.

Competing interests None declared.

\section{Patient consent for publication Not required.}

Ethics approval As a service evaluation comprising only routinely collected data items, ethics committee approval was not required and patient care was not affected. Approval from the local Caldicott guardian was granted. Data are not publicly available as they relate to the care of individuals within the NHS, and permission was granted specifically for use in this project.

Provenance and peer review Not commissioned; externally peer reviewed. 
Data availability statement Data may be obtained from a third party and are not publicly available.

Open access This is an open access article distributed in accordance with the Creative Commons Attribution Non Commercial (CC BY-NC 4.0) license, which permits others to distribute, remix, adapt, build upon this work non-commercially, and license their derivative works on different terms, provided the original work is properly cited, appropriate credit is given, any changes made indicated, and the use is non-commercial. See: http://creativecommons.org/licenses/by-nc/4.0/.

ORCID iD

Christopher Price http://orcid.org/0000-0003-3566-3157

\section{REFERENCES}

1 NHS England. High quality care for all, now and for future generations: Transforming urgent and emergency care services in England - Urgent and Emergency Care Review End of Phase 1 Report, 2013. Available: www.nhs.uk/NHSEngland/keogh-review/ Documents/UECR.Ph1Report.FV.pdf [Accessed 9 Aug 2019].

2 NHS England. Next steps on the NHS five year forward view, 2017. Available: www. england.nhs.uk/publication/next-steps-on-the-nhs-five-year-forward-view [Accessed 9 Aug 2019].

3 MacKenzie EJ, Rivara FP, Jurkovich GJ, et al. A national evaluation of the effect of trauma-center care on mortality. N Engl J Med 2006;354:366-78.

4 Kontos MC, Wang Y, Chaudhry SI, et al. Lower hospital volume is associated with higher in-hospital mortality in patients undergoing primary percutaneous coronary intervention for ST-Segment-Elevation myocardial infarction. Circulation 2013;6:659-67.

5 West RM, Cattle BA, Bouyssie M, et al. Impact of hospital proportion and volume on primary percutaneous coronary intervention performance in England and Wales. Eur Heart J 2011:32:706-11

6 Morris S, Ramsay AIG, Boaden RJ, et al. Impact and sustainability of centralising acute stroke services in English metropolitan areas: retrospective analysis of hospital episode statistics and stroke national audit data. BMJ 2019;364:11.

7 Department of Health \& Social Care NHS England. Reducing emergency admissions. National audit office March 2nd, 2018. Available: https://www.nao.org.uk/report/ reducing-emergency-admissions [Accessed 9 Aug 2019].

8 Soong J, Poots AJ, Scott S, et al. Quantifying the prevalence of frailty in English hospitals. BMJ Open 2015;5:e008456.

9 NHS Benchmarking Network. Older People's Care in Acute Settings: Benchmarking Report, 2016. Available: https://www.nhsbenchmarking.nhs.uk/news/older-peoplescare-in-acute-settings-project-2016-findings-published

10 Bell D, Lambourne A, Percival F, et al. Consultant input in acute medical admissions and patient outcomes in hospitals in England: a multivariate analysis. PLoS One 2013;8:e61476.
11 Nimptsch U, Mansky T. Hospital volume and mortality for 25 types of inpatient treatment in German hospitals: observational study using complete national data from 2009 to 2014. BMJ Open 2017;7:e016184.

12 Vaughan L, Edwards N, Imison C, et al. Rethinking acute medical care in smaller hospitals. Research report, Nuffield trust, 2018. Available: www.nuffieldtrust.org. uk/research/rethinking-acute-medical-care-in-smaller-hospitals [Accessed 9 Aug 2019].

13 Kelly C, Hulme C, Farragher T, et al. Are differences in travel time or distance to healthcare for adults in global North countries associated with an impact on health outcomes? A systematic review. BMJ Open 2016;6:e013059.

14 Postma J, Zuiderent-Jerak T. Beyond volume indicators and centralization: toward a broad perspective on policy for improving quality of emergency care. Ann Emerg Med 2017;69:689-97.

15 Friebel R, Hauck K, Aylin P, et al. National trends in emergency readmission rates: a longitudinal analysis of administrative data for England between 2006 and 2016. BMJ Open 2018;8:e020325.

16 Summary Hospital-level Mortality Indicator (SHMI). NHS digital. Available: https:// digital.nhs.uk/data-and-information/publications/ci-hub/summary-hospital-levelmortality-indicator-shmi [Accessed 29 Jul 2019].

17 Charlson ME, Pompei P, Ales KL, et al. A new method of classifying prognostic comorbidity in longitudinal studies: development and validation. J Chronic Dis 1987:40:373-83

18 Department for Communities and Local Government. The English indices of deprivation, 2015. Available: www.gov.uk/government/statistics/english-indices-ofdeprivation-2015 [Accessed 9 Aug 2019].

19 Fine JP, Gray RJ. A proportional hazards model for the Subdistribution of a competing risk. J Am Stat Assoc 1999;94:496-509.

20 Boyle A, Fuld J, Ahmed V, et al. Does integrated emergency care reduce mortality and non-elective admissions? A retrospective analysis. Emergency Medicine Journal 2012;29:208-12.

21 Boyle AA, Ahmed V, Palmer CR, et al. Reductions in hospital admissions and mortality rates observed after integrating emergency care: a natural experiment. BMJ Open 2012;2:e000930.

22 Knowles E, Shephard N, Stone T, et al. Closing five emergency departments in England between 2009 and 2011: the closED controlled interrupted time-series analysis. Health Serv Deliv Res 2018;6:1-234.

23 Hentschker C, Mennicken R. The Volume-Outcome Relationship and Minimum Volume Standards - Empirical Evidence for Germany. Health Econ 2015;24:644-58.

24 Ross JS, Normand S-LT, Wang Y, et al. Hospital volume and 30-day mortality for three common medical conditions. N Eng/ J Med 2010;362:1110-8.

25 Tsai C-L, Delclos GL, Camargo CA. Emergency department case volume and patient outcomes in acute exacerbations of chronic obstructive pulmonary disease. Acad Emerg Med 2012;19:656-63. 